\title{
Identifikasi Perubahan Indeks Kerapatan Bangunan Pasca Likuifaksi di Kota Palu
}

\author{
Sandi Pranata \\ Teknologi Geomatika, Politeknik Pertanian Negeri \\ Samarinda, Samarinda, 75131 \\ sandipranata61299@gmail.com
}

\author{
Nia Kurniadin* \\ Teknologi Geomatika, Politeknik Pertanian Negeri \\ Samarinda, Samarinda, 75131 \\ niakurniadin@politanisamarinda.ac.id \\ *Corresponding author
}

\begin{abstract}
Abstrak-Kota Palu adalah ibukota dari Provinsi Sulawesi Tengah, Indonesia. Pada tanggal 28 september 2018 telah terjadi bencana alam berupa gempa bumi berkekuatan 7,4 Skala Richter (SR) yang diikuti dengan tsunami, serta likuifaksi yang melanda Kelurahan Petobo dan Balaroa. Gempa bumi, tsunami dan likuifaksi tidak hanya menyebabkan korban jiwa, namun juga menyebabkan kerusakan terhadap bangunan yang ada di Kota Palu dan sekitarnya. Tujuan penelitian ini adalah untuk mengidentifikasi perubahan indeks kerapatan bangunan di Kota Palu pasca likuifaksi menggunakan citra Sentinel-2 tanggal 27 September 2018 dan 2 Oktober 2018. Metode yang digunakan dengan pendekatan Normalized Difference Built-Up Index (NDBI) pada kedua citra sehingga mendapatkan perubahan kerapatan bangunan pasca Likufaksi di Kota Palu. Hasil penelitian menunjukkan bahwa nilai indeks kerapatan bangunan berdasarkan kelas kerapatan nonbangunan, kerapatan bangunan rendah, kerapatan bangunan sedang, dan kerapatan bangunan tinggi secara berturut-turut mengalami perubahan $-605.07 \mathrm{Ha}, 61.07$ $\mathrm{Ha}, 369.36 \mathrm{Ha}$, dan $174.64 \mathrm{Ha}$. Kelurahan Petobo mengalami dampak Likuifaksi $163 \mathrm{Ha}$, sedangkan Kelurahan Balaroa mengalami dampak Likuifaksi 39.54 Ha.
\end{abstract}

Kata Kunci-NDBI, Sentinel-2, Kota Palu, Likuifaksi, Gempa Bumi, Tsunami

\section{PENDAHULUAN}

Kerusakan alam terjadi akibat aktivitas manusia dan bencana alam. Dalam hal terjadinya bencana alam manusia tidak memiliki kemampuan untuk mencegah, namun demikian manusia mempunyai kemampuan untuk mengatasi kerusakan alam secara terbatas. Pada tanggal 28 September 2018, pukul 18.02 WITA, terjadi bencana alam berupa gempa bumi berkekuatan 7,4 Skala Richter (SR) yang diikuti dengan tsunami, serta likuifaksi yang melanda Kelurahan Petobo dan Balaroa. Pusat Gempa berada pada $26 \mathrm{~km}$ utara Donggala dan $80 \mathrm{~km}$ barat laut kota Palu dengan kedalaman $10 \mathrm{~km}$. Akibat bencana tersebut tercatat rumah rusak berat sebanyak 5.025, rusak sedang 5.624 dan rusak ringan 6.000 lebih, dan korban jiwa mencapai 2.113 orang, 1.309 orang hilang, 4.612 luka-luka, dan 223.751 orang mengungsi di 122 titik.
Lebih lanjut dijelaskan bahwa gempa bumi ini berpotensi tsunami di Kota Palu dan sebagian pesisir utara Kabupaten Mamuju. Tsunami ini disebabkan adanya kelongsoran sedimen dalam laut yang mencapai 200-300 meter. Di lain tempat selain Donggala, adanya gempa lokal yang membuat tsunami tak sebesar di Donggala. Di Teluk Palu yang jaraknya lebih dekat dengan pusat gempa diperkirakan lebih dahulu mengalami tsunami setinggi 1,5 meter.

Akibat guncangan gempa bumi, beberapa saat setelah puncak gempa terjadi, muncul gejala likuifaksi (pencairan tanah) yang memakan banyak korban jiwa dan material. Saat terjadinya likuifaksi, terjadi kenaikan dan penurunan muka tanah. Beberapa bagian amblas 5 meter, dan beberapa bagian naik sampai 2 meter. Likuifaksi yang terjadi akibat bencana tersebut dapat dipantau dari data penginderaan jauh. Hal ini dapat diamati dengan melakukan analisis indeks kerapatan bangunan sebelum dan sesudah terjadinya bencana dengan menggunakan dua seri data penginderaan jauh. Hal ini juga dapat diamati dengan melakukan pengolahan data menggunakan algoritma NDBI (Normalized Difference Built-Up Index) untuk memperoleh indeks kerapatan bangunan di Kota Palu.

Indeks NDBI akan fokus untuk menyoroti daerah perkotaan atau kawasan terbangun di mana biasanya ada pemantulan yang lebih tinggi pada area Shortwave Infrared (SWIR), jika dibandingkan dengan area NearInfrared (NIR). Penelitian tentang kerapatan bangunan menggunakan algoritma NDBI pada umumnya menggunakan Citra Satelit Landsat 8, namun pada metode ini menggunakan Citra Satelit Sentinel-2 dikarenakan resolusi yang lebih baik, yaitu resolusi spasial $10 \mathrm{~m}$ dan resolusi temporal 5 hari.

Kondisi kerapatan bangunan pasca likuIfaksi ini perlu diketahui sebagai bahan untuk perencanaan dan pengembangan pembangunan berikutnya. Untuk itu perlu dilakukan penelitian untuk memperoleh kondisi kerapatan bangunan sebelum dan sesudah terjadi bencana di Kota Palu.

\section{STUDI PUSTAKA}

Likuifaksi tanah atau sering disebut likuifaksi gempa adalah keadaan hilangnya kekuatan tanah, sebaliknya, tanah yang tadinya padat menjadi mudah bergeser. 
Fenomena ini terjadi pada tanah yang mengandung banyak air, kemudian terdampak gelombang seismik ketika gempa bumi terjadi, Britannica melansir. Tanah berpasir, berlumpur, dan berkerikil dengan drainase (saluran pembuangan air) buruk rentan terhadap likuifaksi. Selain karena faktor alami, likuifaksi tanah dapat pula terjadi karena peledakan, pemadatan tanah, dan proses vibroflotation (menggunakan alat penggetar untuk mengubah struktur butiran tanah) juga rentan mengalami peristiwa ini (Dayana, 2019).

Tanah terdiri dari komponen penyusun dan ruang pori. Ketika goncangan gempa terjadi di tanah yang kaya atau dekat dengan sumber air, ruang pori terebut terisi air sehingga mengurangi volume keseluruhan tanah. Proses ini meningkatkan tekanan air antara butiran komponen tanah sehingga kemudian butiran tersebut bergerak bebas di antara air dan kehilangan ikatan antarsatu dnegan yang lain. Secara substansial, perubahan ini menurunkan ketahanan tanah terhadap tegangan geser dan menyebabkan massa tanah mengambil karakteristik cairan. Dalam keadaan cair, tanah mudah berubah bentuk, dan benda berat seperti konstruksi di atasnya dapat rusak karena kehilangan kekuatan yang menopang dari dalam tanah. Tanah yang terlikuifikasi akan memberikan dampak seperti pasir hisap, merendam bangunan atau material di atasnya. Terlebih, dapat pula menyebabkan tanah longsor. Likuifaksi tanah ini berdampak pada bangunan di atasnya.

Geography and You (Researcher, 2018) melansir, tanah akan menghisap fondasi bangunan yang tertanam di dalam tanah. Jika tanah terlikuifikasi dalam skala besar, maka bangunan juga akan ikut terhisap masuk ke dalam tanah. Tanah akan tenggelam ke bawah bersamaan dengan bangunan dan dapat terjadi terus menerus. Lapisan antara tanah dan lantai bangunan juga akan mengalami kerusakan. Air dari tanah mulai mengalir ke sela-sela tembok bangunan dan lantai bangunan yang rusak dan iut merusak peralatan serta sambungan elektronik. Oleh karena itu, likuifaksi tanah dapat membahayakan manusia, terlebih jika terjadi di area pemukiman penduduk.

Ada beberapa cara untuk mengatasi likuifaksi tanah, sebagaimana dilansir Science Direct (Direct, 2020), di antaranya modifikasi fisik, densifikasi, mengangkat tekanan air di pori-pori tanah, dan penguatan fondasi bangunan. Cara tersebut adalah cara konvensional, yaitu meningkatkan kepadatan relatif pada pasir. Upaya ini memerlukan perawatan intensif dan terus menerus. Penerapan tersebut biasanya memakan biaya sangat besar karena besaran tanah yang hendak diatasi biasanya luas, oleh karena itu ada solusi yang lebih hemat biaya untuk pengolahan cairan.

Pendekatan baru untuk mitigasi (mengurangi dampak bencana) karena likuifaksi tanah adalah dengan memasukkan gelembung gas ke dalam tanah. Gelembung gas akan mengurangi kelebihan pori air di tanah dan bebannya akan berkurang cukup signifikan. Sebagai alternatif, memasukkan gelembung gas ke dalam tanah menggunakan mikroorganisme. Metode ini disebut desaturasi biogas (Wu et al., 2017). Dalam riset ini, didapati beberapa sampel tanah mengandung air diguncang dengan getaran di bawah percepatan 1,5 $\mathrm{m} /$ detik, dan air pori tanah menunjukkan kejenuhan air sebesar 80 persen. Metode desaturasi biogas kemudian dilakukan dan menunjukkan jumlah tekanan air pori berkurang secara signifikan, dengan tingkat efektivitas mencapai 90 persen. Metode ini cukup menjanjikan karena mengonsumsi energi paling sedikit, bakteri viskositas rendah, dan cairan nutrisi dapat dengan mudah dimasukkan ke pasir. Gas yang dihasilkan oleh bakteri dapat didistribusikan lebih merata, dan gelembung gas yang dihasilkan oleh bakteri kecil sehingga gelembung gas itu tidak mudah lepas dari tanah. Metode biogas efektif dalam mencegah terjadinya pencairan tanah serta mengurangi kerusakan yang disebabkan cairan dalam tanah.

Penginderaan jauh (remote sensing) sering disingkat inderaja, adalah ilmu dan seni untuk memperoleh informasi tentang suatu obyek, daerah, atau fenomena melalui analisis data yang diperoleh dengan suatu alat tanpa kontak langsung dengan obyek, daerah, atau fenomena yang dikaji (Lillesand \& Kiefer, 1990). Penginderaan jauh berasal dari dua kata dasar yaitu indera berarti melihat dan jauh berarti dari jarak jauh. Jadi berdasarkan asal katanya, penginderaan jauh berarti melihat obyek dari jarak jauh. Obyek, daerah, atau gejala yang dikaji dalam definisi tersebut dapat berada di permukaan bumi, di atmosfer, atau planet di luar angkasa. Sistem penginderaan jauh ialah serangkaian komponen yang digunakan untuk penginderaan jauh. Rangkaian komponen itu berupa tenaga, objek, sensor, data dan pengguna data. Karena tidak semua tenaga yang berasal dari matahari dapat mencapai bumi, interaksi antara tenaga dan atmosfer sering dimasukkan ke dalam sistem penginderaan jauh. Demikian pula halnya dengan interaksi antara tenaga dan objek, karena hasil interaksinya menentukan besarnya tenaga yang dapat mencapai sensor (Ardiansyah, 2018).

Sistem penginderaan jauh mempunyai empat komponen dasar untuk mengukur dan merekam data mengenai sebuah wilayah dari jauh. Komponen ini yaitu sumber energi, target, sensor, dan wilayah transmisi. Sumber energi disini yang terpenting adalah energi elektromagnetik, dimana merupakan medium penting yang diperlukan untuk mentransmisikan informasi dari obyek ke sensor. Penginderaan jauh menyediakan bentuk tutupan lahan yang penting yaitu luasan, pemetaan dan klasifikasi seperti vegetasi, tanah air dan hutan. Citra digital yang diperoleh dari perekaman oleh sensor pada dasarnya tidak lepas dari kesalahan, karena kondisi topografi permukaan bumi yang bervariasi serta luasan permukaan bumi. Sementara wahana dan sistem penginderaan jauh mempunyai keterbatasan dalam resolusi spasial, spektral, temporal maupun radiometri. Kesalahan- kesalahan tersebut diakibatkan oleh mekanisme perekaman sensor, gerakan serta kondisi atmosfer pada saat perekaman, sehingga citra digital tidak bisa digunakan untuk analisis. Kesalahan-kesalahan tersebut perlu dihilangkan terlebih dahulu sebelum dilakukan analisis (Sutanto, 1994). 
Sensor adalah sebuah alat yang mengumpulkan dan mencatat radiasi elektromagnetik. Setelah melalui proses pencatatan dan akan dikirim ke stasiun penerima dan diproses menjadi format yang siap dipakai, diantaranya berupa citra. Citra ini kemudian diinterpretasikan untuk mencarikan informasi mengenai target. Proses interpretasi biasanya gabungan antara visual dan automatik dengan bantuan Komputer dan perangkat lunak pengolahan citra. Sensor sangatlah terbatas untuk mengindera obyek yang sangat kecil, batas kemampuan sensor untuk memisahkan setiap obyek dinamakan resolusi, resolusi suatu sensormerupakan indikator tentang kemampuan sensor atau kualitas sensor dalam merekam suatu obyek (Angga, 2017).

Sentinel-2 terdiri dari dua satelit konstelasi yaitu Sentinel-2A dan Sentinel-2B yang mengorbit kutub pada orbit sun-synchronous pada ketinggian $786 \mathrm{~km}$. Dua satelit identik tersebut berjarak 180 derajat satu sama lain. Satelit tersebut merupakan satelit resolusi menengah dengan resolusi temporal 10 hari untuk satu satelit atau 5 hari dengan dua satelit. Satelit ini dapat digunakan untuk pengamatan operasional seperti peta tutupan lahan, peta deteksi perubahan lahan dan variabel geofisika. Data Sentinel-2 L1C terdiri dari 13 band spektral dengan rincian: resolusi spasial $10 \mathrm{~m}$ sebanyak 4 band (B2, B3, B4, B8); resolusi spasial $20 \mathrm{~m}$ sebanyak 6 band (B5, B6, B7, B8A, B11, B12); dan resolusi spasial $60 \mathrm{~m}$ sebanyak 3 band (B1, B9, B10). Luas cakupan sebesar $290 \mathrm{~km}$. Data Sentinel-2 tersebut merupakan data Level-1C (Reflektan ToA). Produk tersebut telah diproyeksikan ortho UTM/WGS84. Produk ini menggunakan Model Elevasi Digital (DEM) yang diproyeksikan pada koordinat kartografi (ESA, 2015).

Tabel 1. Sensor Band Spektral Sentinel-2 (S2A \& S2B)

\begin{tabular}{|c|c|c|c|c|c|}
\hline \multirow[b]{2}{*}{ Band } & \multicolumn{2}{|c|}{ S2A } & \multicolumn{2}{|c|}{ S2B } & \multirow[b]{2}{*}{$\begin{array}{c}\text { Resolusi } \\
\text { Spasial } \\
\text { (m) }\end{array}$} \\
\hline & $\begin{array}{c}\text { Sentral } \\
\text { Panjang } \\
\text { Gelombang } \\
(\mathrm{nm})\end{array}$ & $\begin{array}{l}\text { Lebar } \\
\text { Saluran } \\
(\mathrm{nm})\end{array}$ & $\begin{array}{c}\text { Sentral } \\
\text { Panjang } \\
\text { Gelombang } \\
(\mathrm{nm})\end{array}$ & $\begin{array}{l}\text { Lebar } \\
\text { Saluran } \\
(\mathrm{nm})\end{array}$ & \\
\hline 1 & 442,7 & 21 & 442,3 & 21 & 60 \\
\hline 2 & 492,4 & 66 & 492,1 & 66 & 10 \\
\hline 3 & 559,8 & 36 & 559,0 & 36 & 10 \\
\hline 4 & 664,6 & 31 & 665,0 & 31 & 10 \\
\hline 5 & 704,1 & 15 & 703,8 & 16 & 20 \\
\hline 6 & 740,5 & 15 & 739,1 & 15 & 20 \\
\hline 7 & 782,8 & 20 & 779,7 & 20 & 20 \\
\hline 8 & 832,8 & 106 & 833,0 & 106 & 10 \\
\hline $8 \mathrm{~A}$ & 864,7 & 21 & 864,0 & 22 & 20 \\
\hline 9 & 945,1 & 20 & 943,2 & 21 & 60 \\
\hline 10 & 1373,5 & 31 & 1376,9 & 30 & 60 \\
\hline 11 & 1613,7 & 91 & 1610,4 & 94 & 20 \\
\hline 12 & 2202,4 & 175 & 2183,7 & 185 & 20 \\
\hline
\end{tabular}

(ESA, 2020)

Normalized Difference Built-up Index (NDBI) merupakan indeks yang menggunakan saluran inframerah tengah dan inframerah dekat. Indeks NDBI akan fokus untuk menyoroti daerah perkotaan atau kawasan terbangun di mana biasanya ada pemantulan yang lebih tinggi pada area Shortwave Infrared (SWIR), jika dibandingkan dengan area Near-Infrared (NIR). NDBI yang disebut juga Normalized Difference Built-up Index dan UI (Urban Index) merupakan indeks yang sangat sensitif terhadap lahan terbangun/lahan terbuka yang dikembangkan untuk menonjolkan kenampakan lahan terbangun dibandingkan dengan obyek yang lainnya (Kurniawan et al., 2017).

Indeks lahan terbangun atau NDBI merupakan algoritma untuk menunjukkan tingkat kerapatan lahan terbangun. Nilai NDBI sangat dipengaruhi oleh lahan terbangun maupun lahan yang terbuka (Guo et al., 2015). Indeks lahan terbangun dapat dideteksi menggunakan algoritma Normalized Difference Built-up Index (NDBI) yang sangat sensitive terhadap lahan terbangun dan lahan terbuka. Pemilihan algoritma NDBI dilakukan karena formula ini adalah yang paling banyak digunakan dalam mengkaji indeks lahan terbangun (Handayani et al., 2017).

Nilai kerapatan bangunan yang akan diperoleh yaitu antara -1 sampai dengan 1. Kerapatan bangunan diklasifikasikan menjadi 4 kelas yaitu -1 sampai -0,15 (non bangunan), lebih dari -0,15 sampai -0,1 (rendah), lebih dari -0,1 sampai 0,1 (sedang), dan lebih dari 0,1 sampai 1 (tinggi).

Tabel 2. Kelas Kerapatan Bangunan

\begin{tabular}{|c|c|c|}
\hline Kelas & Nilai & Keterangan \\
\hline Kelas 1 & $-1 \leq \mathrm{NDBI} \leq-0,15$ & Non Bangunan \\
\hline Kelas 2 & $-0,15<\mathrm{NDBI} \leq-0,1$ & Kerapatan Bangunan Rendah \\
\hline Kelas 3 & $-0,1<\mathrm{NDBI} \leq 0,1$ & Kerapatan Bangunan Sedang \\
\hline Kelas 4 & $0,1<\mathrm{NDBI} \leq 1$ & Kerapatan Bangunan Tinggi \\
\hline
\end{tabular}

(Sumber: Hardyanti, Sobirin dan Wibowo, 2017)

\section{METODOLOGI}

\section{A. Lokasi Penelitian}

Lokasi sebagai objek penelitian ini adalah wilayah Kota Palu yang secara administratif terletak di Provinsi Sulawesi Tengah, berbatasan dengan Kabupaten Donggala di sebelah barat dan utara, Kabupaten Sigi di sebelah selatan, dan Kabupaten Parigi Moutong di sebelah timur. Secara geografis terletak di antara $0^{\circ} 36^{\prime}-$ $0^{\circ} 56^{\prime}$ Lintang Selatan dan $119^{\circ} 45^{\prime}-120^{\circ} 01^{\prime}$ Bujur Timur. Pemilihan lokasi penelitian berdasarkan hasil studi literatur dan analisis data historis bencana Gempa Bumi, Tsunami dan Likuifaksi yang terjadi pada tanggal 28 September 2018. Lokasi penelitian ditunjukkan pada Gambar 1 berikut:

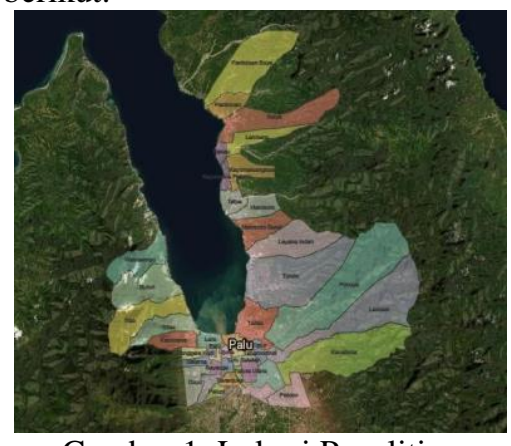

Gambar 1. Lokasi Penelitian

\section{B. Data dan Peralatan}

Data yang digunakan dalam penelitian ini adalah data citra satelit Sentinel-2 level 1C wilayah Kota Palu 
perekaman tanggal 27 September 2018 dan tanggal 2 Oktober 2018, batas administrasi Kota Palu dari InaGeoportal, dan batas area terdampak likuifaksi Kota Palu dari BNPB.

Perangkat lunak yang digunakan dalam penelitian ini adalah Quantum GIS 3.10 beserta Semi-Automatic Classification Plugin yang telah terpasang untuk melakukan koreksi atmosfer menggunakan metode Dark Object Subtraction, digitasi awan, pemotongan citra, perhitungan dan clasifikasi NDBI dan pembuatan layout peta.

\section{Pengumpulan dan Pengolahan Data}

Pengumpulan data yang terdiri dari data batas administrasi Kota Palu dan data citra Sentinel-2 sebelum dan setelah terjadinya Gempa Bumi, Tsunami dan Likuifaksi yang terjadi pada tanggal 28 September 2018. Data citra yang diperoleh dari laman https://scihub.copernicus.eu/dhus/\#/home terdiri dari citra Sentinel-2 tanggal 27 September 2018 (S2B_MSIL1C_20180927T022319_N0206_R103_T50M RE_20180927T055542) dan tanggal 2 Oktober 2018 (S2A_MSIL1C_20181002T022321_N0206_R103_T50M RE_20181002T054141).

Pengolahan data diawali dengan koreksi atmosferik. Koreksi atmosfer bertujuan untuk menurunkan reflektan objek dari total radiansi ToA setelah proses normalisasi kondisi pencahayaan dan penghapusan efek atmosfer. Koreksi dilakukan dengan menggunakan metode Dark Object Subtraction (DOS) pada perangkan lunak Quantum GIS.

Pengolahan selanjutnya adalah cloud masking atau menghilangkan objek awan yang ada pada citra yang digunakan. Proses cloud masking pada penelitian ini dilakukan secara manual yaitu dengan melakukan digitasi objek awan pada citra tanggal 27 September 2018 dan citra tanggal 2 Oktober 2018. Hasil cloud masking tersebut selanjutnya digabung (dengan metode Union) untuk dijadikan sebagai pemotong kedua citra agar daerah yang berawan di kedua citra tidak termasuk dalam proses selanjutnya.

Tahap selanjutnya adalah pemotongan citra sesuai dengan areal studi yang bertujuan untuk memfokuskan pengolahan pada wilayah kajian, serta pemotongan citra menggunakan hasil digitasi awan. Hal ini bertujuan agar citra yang dianalisis sesuai dengan batas administrasi kota palu dan bebas dalam tutupan awan, dengan memotong kedua citra dengan hasil dari proses digitasi sebelumnya agar data yang di analisis bebas dari tutupan awan karena pada kedua citra memiliki tutupan awan yang berbeda, sehingga area yang dianalisis memiliki luasan sama yang menjadi objek penelitian.

Penerapan algoritma NDBI (Normalized Difference Built-up Index) yang sangat sensitif terhadap lahan terbangun/lahan terbuka yang dikembangkan untuk menonjolkan kenampakan lahan terbangun dibandingkan dengan obyek yang lainnya. NDBI dilakukan dengan mengombinasikan antara saluran inframerah tengah (band 11) dan saluran inframerah dekat (band 8) citra Sentinel-2 yang telah terkoreksi atmosfer menjadi nilai indeks kerapatan bangunan. Persamaan yang digunakan untuk mendapatkan nilai NDBI adalah sebagai berikut:

dimana:

$$
\mathrm{NDBI}=(\mathrm{SWIR}-\mathrm{NIR}) /(\mathrm{SWIR}+\mathrm{NIR})
$$

NDWI = Nilai Normalized Difference Built-up Index

SWIR = Nilai reflektan dibawah lapisan atmosfer untuk kanal 11 (inframerah tengah)

NIR = Nilai reflektan dibawah lapisan atmosfer untuk kanal 8 (inframerah dekat)

Klasifikasi NDBI dilakukan untuk mengetahui luasan berdasarkan tingkat kerapatan bangunan, mulai dari nonbangunan, kelas kerapatan bangunan rendah, sedang dan tinggi. Dilakukan pula analisis terhadap perubahan tingkat kerapatan bangunan untuk wilayah terdampak likuifaksi, yaitu kelurahan Petobo dan kelurahan Balaroa.

Tahap layouting peta dilakukan dengan memanfaatkan data hasil pengolahan citra Sentinel-2 berdasarkan klasifikasi kelas kerapatan bangunan yang diperoleh dari hasil pengolahan NDBI. Peta yang dihasilkan berupa peta kerapatan bangunan kota palu sebelum dan setelah likuifaksi yang terjadi pada tanggal 28 September 2018.

\section{HASIL DAN PEMBAHASAN}

Hasil penelitian Identifikasi Perubahan Indeks Kerapatan Bangunan pasca Likuifaksi di Kota Palu menggunakan Citra Sentinel-2 dengan perekaman tanggal 27 September 2018 dan 02 Oktober 2018 dengan perangkat lunak Quantum GIS berupa nilai indeks kerapatan bangunan sebelum dan setelah likuifaksi di Kota Palu. Dari hasil pengolahan diperoleh bahwa untuk citra perekaman tanggal 27 September 2018 nilai NDBI terendah dan tertinggi berturut-turut $-0,732$ dan 0,652 , sedangkan untuk citra perekaman tanggal 2 Oktober 2018 nilai NDBI terendah dan tertinggi berturut-turut $-0,729$ dan 0,666. Nilai luas setiap kelas kerapatan bangunan di Kota Palu setelah dikurangi luas wilayah yang tertutup awan disajikan pada Tabel 3 .

Tabel 3. Luas Tingkat Kerapatan Bangunan

\begin{tabular}{|l|c|c|c|}
\hline \multicolumn{1}{|c|}{ Kelas } & $\begin{array}{c}\text { Sebelum } \\
\text { Likuifaksi } \\
(\mathrm{Ha})\end{array}$ & $\begin{array}{c}\text { Setelah } \\
\text { Likuifaksi } \\
(\mathrm{Ha})\end{array}$ & $\begin{array}{c}\text { Perubahan } \\
\text { Luas (Ha) }\end{array}$ \\
\hline Non Bangunan & $6.626,41$ & $6.021,34$ & $-605,07$ \\
\hline $\begin{array}{l}\text { Kerapatan } \\
\text { Bangunan Rendah }\end{array}$ & $1.448,23$ & $1.509,30$ & 61,07 \\
\hline $\begin{array}{l}\text { Kerapatan } \\
\text { Bangunan Sedang }\end{array}$ & $10.473,27$ & $10.842,63$ & 369,36 \\
\hline $\begin{array}{l}\text { Kerapatan } \\
\text { Bangunan Tinggi }\end{array}$ & $6.877,38$ & $7.052,02$ & 174,64 \\
\hline
\end{tabular}

Setelah dilakukan interpretasi terhadap citra hasil pengolahan NDBI untuk mengetahui perubahan luas area terdampak likuifaksi di kelurahan Petobo dan Balaroa diperoleh perbedaan hasil jika dibandingkan dengan data yang diperoleh dari BNPB. Terdapat selisih 13 Ha untuk kelurahan Petobo dan 8,42 Ha untuk kelurahan Balaroa (Tabel 4). Perbedaan luas tersebut dipengaruh oleh jenis data spasial yang berbeda, data dari BNPB berupa data vektor (polygon), sedangkan data yang digunakan untuk interpretasi berupa data raster (dengan resolusi $10 \mathrm{~m} \mathrm{x}$ 
$10 \mathrm{~m}$ per piksel). Setelah dilakukan pemotongan pada daerah terdampak terdapat beberapa piksel yang kosong, seperti disajikan pada Gambar 2.

Tabel 4. Luas Area Terdampak Likuifaksi

\begin{tabular}{|l|c|c|c|}
\hline Kelurahan & $\begin{array}{c}\text { Luas } \\
\text { Wilayah } \\
\text { (Ha) }\end{array}$ & $\begin{array}{c}\text { Luas } \\
\text { Terdampak } \\
\text { Hasil } \\
\text { Interpretasi } \\
\text { (Ha) }\end{array}$ & $\begin{array}{c}\text { Luas } \\
\text { Terdampak } \\
\text { Data BNPB } \\
\text { (Ha) }\end{array}$ \\
\hline Petobo & 791,33 & 163,00 & 180,00 \\
\hline Balaroa & 143,06 & 39,54 & 48,00 \\
\hline
\end{tabular}

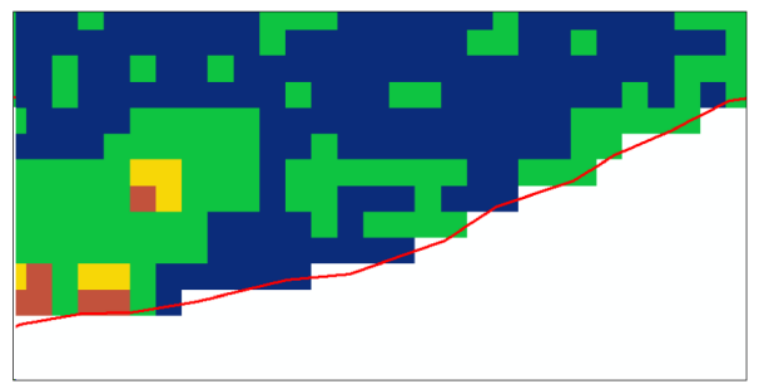

Gambar 2. Overalay Batas Vektor dan Raster Area Terdampak

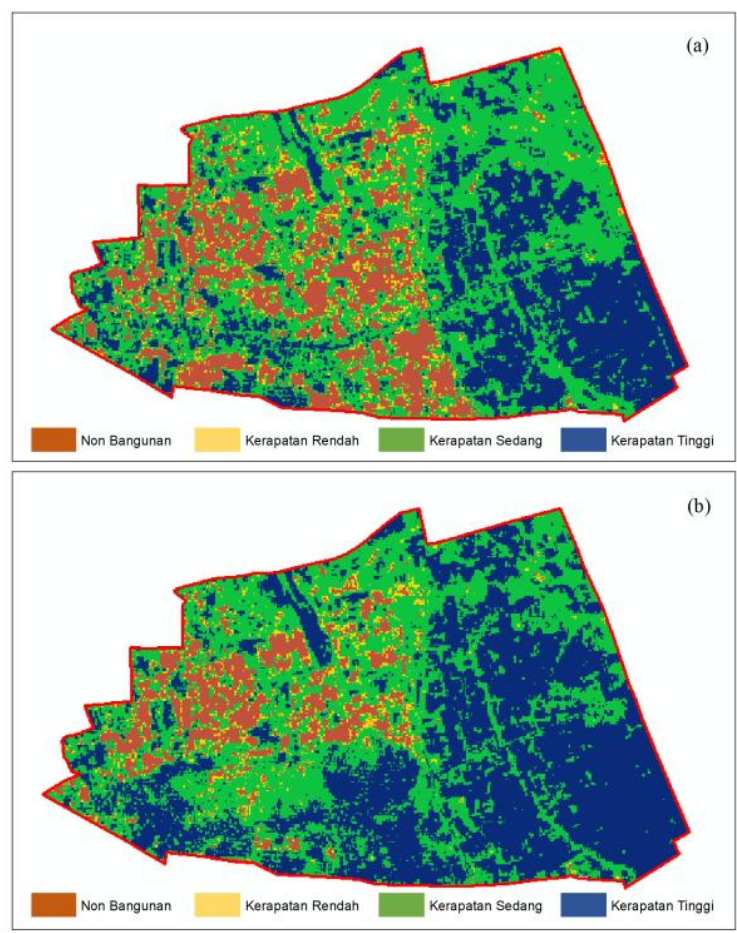

Gambar 3. Kerapatan Bangunan Kelurahan Petobo, (a) Sebelum Likuifaksi, (b) Setelah Likuifaksi.

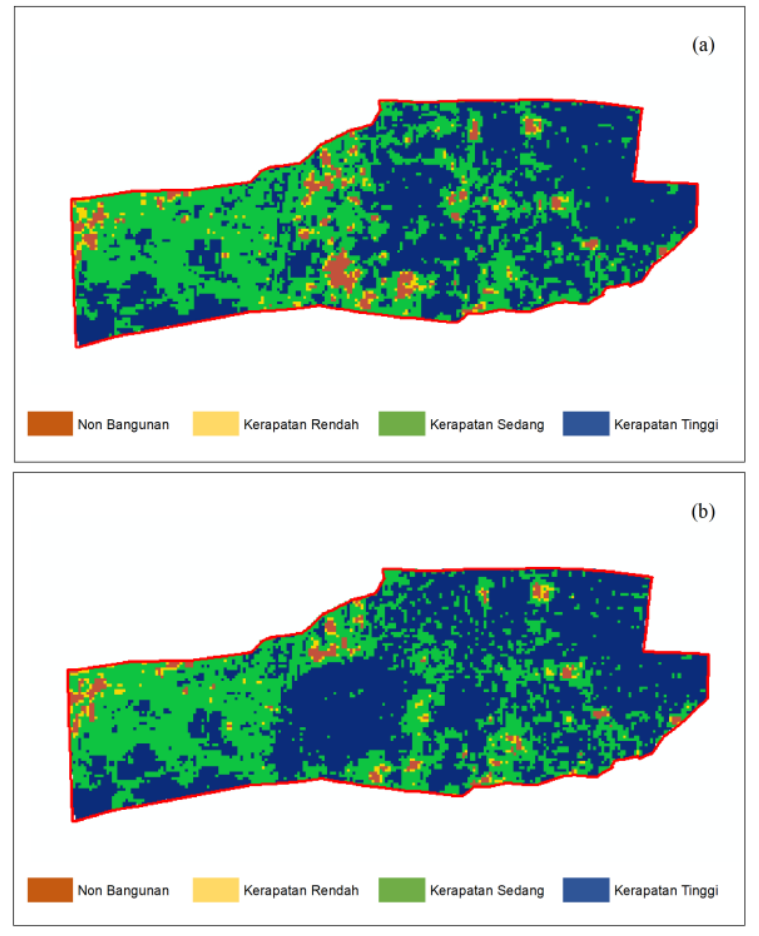

Gambar 4. Kerapatan Bangunan Kelurahan Balaroa, (a) Sebelum Likuifaksi, (b) Setelah Likuifaksi.

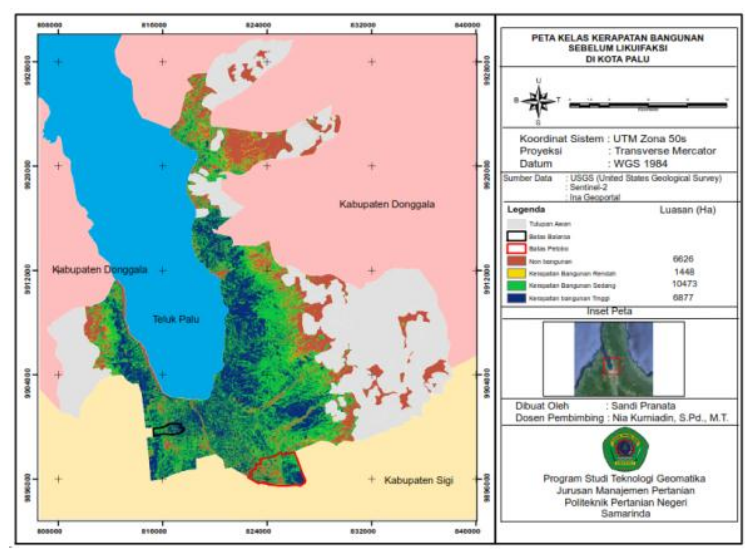

Gambar 5. Peta Kelas Kerapatan Bangunan Kota Palu Sebelum Likuifaksi

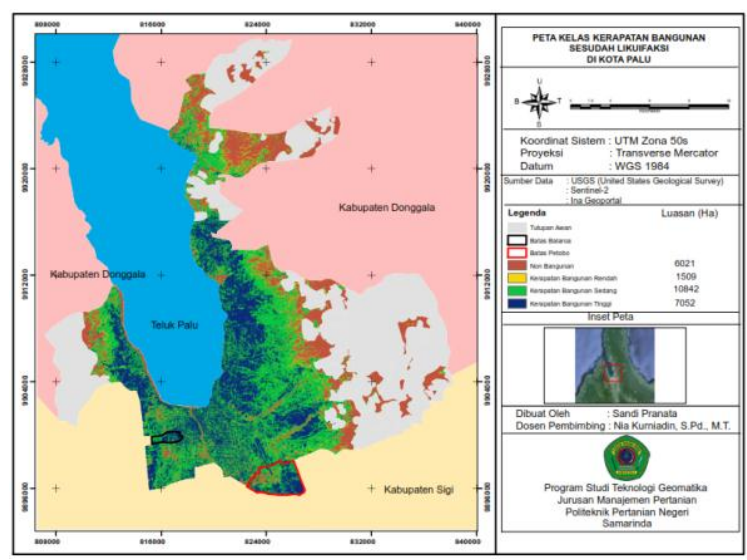

Gambar 6. Peta Kelas Kerapatan Bangunan Kota Palu Setelah Likuifaksi 
Dari pengolahan citra sentinel perekaman tanggal 28 September 2018 dan tanggal 02 Oktober 2018, diperoleh informasi bahwa untuk area yang terdeteksi sebagai area terbangun juga meliputi lahan kering, sehinga nilai kerapatan pada area terbangun tidak sepenuhnya bangunan, dapat dilihat pada kelas kerapatan bangunan tinggi yang mengalami kenaikan akibat banyak nya lahan kering setelah terjadi likuifaksi di Kota Palu. Hal ini terjadi dikarenakan objek area terbangun akan tergambarkan lebih tinggi pada saluran SWIR dibandingkan NIR. Namun, dalam beberapa kasus, lahan kering dan area terbangun memiliki kesamaan karakteristik sehingga nilai saluran SWIR akan lebih tinggi dibandingkan NIR (Kurniawan et al., 2017). Hal ini terjadi pada wilayah kelurahan Petobo dan Balaroa yang mengalami likuifaksi. Kondisi nilai kerapatan bangunan di kelurahan Petobo dan Balaroa, sebelum dan setelah terjadi likuifaksi tanggal 28 Setember 2018 disajikan pada Gambar 3 dan Gambar 4. Sedangakan peta kelas kerapatan bangunan Kota Palu sebelum dan setelah likuifaksi disajikan pada Gambar 5 dan Gambar 6.

\section{KESIMPULAN}

Berdasarkan hasil penelitian dapat disimpulkan bahwa dengan penggunakan citra Sentinel-2 dan menerapkan metode klasifikasi NDBI, diperoleh nilai indeks kerapatan bangunan berdasarkan kelas kerapatan nonbangunan, kerapatan bangunan rendah, kerapatan bangunan sedang, dan kerapatan bangunan tinggi secara berturut-turut mengalami perubahan $-605.07 \mathrm{Ha}, 61.07$ Ha, 369.36 Ha, dan 174.64 Ha. Luas daerah terdampak likuifaksi di kelurahan Petobo dan Balaroa berdasarkan interpretasi citra berturut-turut $163 \mathrm{Ha}$ dan 39,54 Ha, sedangkan luas terdampak berdasarkan data BNPB berturut-turut $180 \mathrm{Ha}$ dan $48 \mathrm{Ha}$. Perbedaan tersebut dikarenakan perbedaan jenis data spasial, data dari BNPB berupa data vektor (polygon), sedangkan data yang digunakan untuk interpretasi berupa data raster (dengan resolusi $10 \mathrm{~m} \times 10 \mathrm{~m}$ per piksel).

\section{DAFTAR PUSTAKA}

Angga, F. S. (2017). Analisis Kerapatan Vegetasi pada Kawasan Pesisir Kabupaten Serdang Bedagai Berbasis Sistem Informasi Geografis. Universitas Sumatra Utara.

Ardiansyah, T. (2018). Penginderaan Jauh: Pengertian, Prinsip, Jenis, dan Manfaat. ForesterAct: Media Kehutanan dan Lingkungan Hidup. https://foresteract.com/penginderaan-jauh/

Dayana, A. S. (2019). Mengenal Likuifaksi Tanah, Penyebab, Dampak dan Pengelolaannya. Tirto.id. https://tirto.id/mengenal-likuifaksi-tanah-penyebabdampak-dan-pengelolaannya-ehLY

Direct, S. (2020). Soil Liquefaction - an Overview. Science Direct. https://www.sciencedirect.com/topics/engineering/soil -liquefaction
ESA. (2015). Sentinel-2 User Handbook. In ESA Standard Document (Vol. 1, Nomor 1). European Space Agency.

ESA. (2020). MultiSpectral Instrument (MSI) Overview. Sentinel Online, The European Space Agency. https://sentinel.esa.int/web/sentinel/technicalguides/sentinel-2-msi/msi-instrument

Guo, G., Wu, Z., Xiao, R., Chen, Y., Liu, X., \& Zhang, X. (2015). Impacts of Urban Biophysical Composition on Land Surface Temperature in Urban Heat Island Clusters. Landscape and Urban Planning, 135 , $1-10$. https://doi.org/10.1016/j.landurbplan.2014.11.007

Handayani, M., Sasmito, B., \& Wijaya, A. (2017). Analisis Hubungan Antara Perubahan Suhu Dengan Indeks Kawasan Terbangun Menggunakan Citra Landsat (Studi Kasus: Kota Surakarta). Jurnal Geodesi Undip, 6(4), 208-2018.

Hardyanti, L., Sobirin, \& Wibowo, A. (2017). Variasi Spasial Temporal Suhu Permukaan Daratan di Kota Jakarta tahun 2015 dan 2016. Prosiding Industrial Research Workshop and National Seminar, 8(3), 704713.

Kurniawan, S., Nurhaidar, W. O., \& Salihin, I. (2017). Optimalisasi Transformasi Spektral UI, NDBI, NDVI dan Kombinasi Transformasi Spektral II-NDBI dan NDBI-NDVI Guna Mendeteksi Kepadatan Lahan Terbangun di Kota Magelang. Jurnal Geografi Aplikasi dan Teknologi, 1(1), 13-22.

Lillesand, T. M., \& Kiefer, R. W. (1990). Remote Sensing and Image Interpretation. Gadjah Mada University Press.

Researcher, S. (2018). What is soil liquefaction? Causes, effects and measures. Geography and You. https://geographyandyou.com/what-is-soilliquefaction/

Sutanto. (1994). Penginderaan Jauh Jilid 2 (2 ed.). Gadjah Mada University Press.

Wu, S., Chu, J., \& He, J. (2017). Mitigation of Liquefaction using Biogas Desaturation. International Conference on Soil Mechanics and Geotechnical Engineering, 2681-2684. https://doi.org/10.1007/9783-319-73568-9_174 